\title{
FAD Analogues as Mechanistic and 'Binding-Domain' Probes of Spinach Ferredoxin-NADP ${ }^{+}$Reductase $^{-}$
}

\author{
Giuliana ZANETTI, Vincent MASSEY, and Bruno CURTI \\ Department of General Physiology and Biochemistry, Faculty of Sciences, University of Milan; and \\ Department of Biological Chemistry, The University of Michigan, Ann Arbor
}

(Received October 19, 1982/January 17, 1983) - EJB 6113

The native flavin, FAD, of spinach ferredoxin $-\mathrm{NADP}^{+}$reductase, has been replaced by a number of $\mathrm{FAD}$ analogues with modifications of the isoalloxazine ring system. The apoenzyme binds 8-mercapto-FAD in its thiolate anion form and 6-hydroxy-FAD in its neutral form. These results are consistent with classification of this enzyme as a dehydrogenase/electron transferase, an ascription originally made on the basis of its physiological function and in common with other properties of this class, e.g. stabilization of the neutral flavin semiquinone.

The chemical reactivity toward methylmethanethiolsulfonate of the 8-mercapto-FAD - enzyme clearly shows that the flavin 8-position is exposed to solvent. On the other hand, the lack of reactivity with the 2-thio-FAD - enzyme indicates that the pyrimidine subnucleus of the flavin is buried within the protein molecule. The seven modified flavins examined all support NADPH-ferricyanide reductase activity, the catalytic velocity being directly proportional to the redox potential of the flavin. No such linear free energy relationship was found between redox potential and activity with ferredoxin or iodonitrotetrazolium as acceptor.

The availability of several new flavin analogues at the FAD level in recent years has been of great advantage in the elucidation of the active site of many flavoproteins [1]. The modified flavins have been used both as probes to examine the influence of the protein on the flavin coenzyme and as a means to investigate solvent accessibility of the protein-bound flavin $[1-4]$. These studies are particularly useful in the case of flavoproteins where the three-dimensional structure is lacking or is at an initial stage. On the other hand, where the X-ray studies have been carried out at good resolution [5-7], further insights could be obtained by comparison of the structural data with those obtained using flavin analogues. In addition, a comparative examination of the different behaviour towards modified flavins has allowed a more rational subdivision of flavoproteins among the various subclasses $[1,3]$. In this regard, 8-chloro, 8-mercapto, 6-hydroxy and 2-thio substituted flavins have been particularly useful $[3,4,8]$. Preliminary to such studies is the availability of a reconstitutable apoprotein of the corresponding flavoenzyme.

Ferredoxin-NADP ${ }^{+}$reductase belongs to the class of the flavin dehydrogenases/electron transferases [1]. Many kinetic and physicochemical properties of the enzyme have been investigated [9], whereas sequential and three-dimensional studies are at a very early stage [10]. Up to now, the use of flavin analogues with this enzyme has been hampered by the lack of an easily reconstitutable apoprotein. We recently succeeded in preparing such an apoferredoxin - $\mathrm{NADP}^{+}$reductase [11]: the

This paper is dedicated to the memory of Peter Hemmerich whose pioneering work on modified flavins and whose stimulating and provocative discussions over many years have played an important role in the present work.

Abbreviations. Iodonitrotetrazolium, 2-(p-iodophenyl)-3-nitrophenyl5-phenyltetrazolium chloride; $\mathrm{Me}_{2} \mathrm{SO}_{2} \mathrm{~S}$, methylmethanethiolsulfonate.

Enzymes. Ferredoxin-NADP ${ }^{+}$reductase (EC 1.18.1.2); isocitrate dehydrogenase (EC 1.1.1.42); flavokinase or riboflavin kinase (EC 2.7.1.26); FAD synthetase or ATP:FMN adenylyl transferase (EC 2.7.7.2); superoxide dismutase (EC 1.15.1.1). result prompted us to investigate the reactivity of flavin analogues with our preparation. In this paper, we report on some properties of apoferredoxin- $\mathrm{NADP}^{+}$reductase reconstituted with 8-Cl-FAD, 8-mercapto-FAD, 6-OH-FAD, 2thio-FAD and 1-deaza-FAD. Furthermore, the exposure to solvent of the protein-bound flavin was investigated.

\section{MATERIALS AND METHODS}

Ferredoxin-NADP ${ }^{+}$reductase from spinach leaves was purified as in [9]. Apoferredoxin- $\mathrm{NADP}^{+}$reductase was prepared by incubation of holoenzyme with $2.5 \mathrm{M} \mathrm{CaCl}_{2}$ according to the procedure described in [11]. Reconstitution with substituted FAD was accomplished by incubating the apoprotein with an excess of the cofactor at $4^{\circ} \mathrm{C}$.

8-Cl-FAD, 2-thio-FAD, 6-OH-FAD and 1-deaza-FAD were prepared from the corresponding riboflavin derivatives by incubation with the flavokinase/FAD synthetase system of Brevibacterium ammoniagenes [12]; 8-mercapto-FAD was prepared by treatment of 8-Cl-FAD with $\mathrm{Na}_{2} \mathrm{~S}$ as described [13]. 8Cl-riboflavin was a gift from Dr J. P. Lambooy (University of Maryland); 1-deaza-riboflavin was a gift from Dr E. F. Rogers (Merck, Sharp and Dohme, Rahway, New Jersey) and 2-thioriboflavin and 6-OH-riboflavin were gifts from the late Professor Peter Hemmerich (University of Konstanz). Methylmethanethiosulfonate was a generous gift from $\mathrm{Dr}$ Jules Shafer (University of Michigan). Iodoacetic acid and iodoacetamide were obtained from the Sigma Chemical Co. All other reagents were of analytical grade.

Absorption spectra and kinetics were determined with a Cary 118 or 219 recording spectrophotometer at $4^{\circ} \mathrm{C}$ or $25^{\circ} \mathrm{C}$. Activity measurements were performed as in $[9,14]$. In reduction experiments, anaerobic $1-\mathrm{ml}$ cells equipped with sidearms were made anaerobic by several cycles of evacuation and refilling with nitrogen purified by storage over Fieser's solution. The NADPH-regenerating system employed in some experiments consisted of the following components in a volume 
of $1 \mathrm{ml}: 10 \mu \mathrm{M}$ NADPH, $2.5 \mathrm{mM}$ DL-isocitrate, $20 \mu \mathrm{g}$ isocitrate dehydrogenase, $5 \mathrm{mM} \mathrm{MgCl}{ }_{2}$. Isoelectrofocusing was performed on gel slabs using a $\mathrm{pH}$ gradient of 4-8 [15]. Activity and protein stainings were carried out as described in [16].

\section{RESULTS}

Binding of 8-Mercapto-FAD to Apoferredoxin-NADP ${ }^{+}$Reductase

and Reduction of the Holoenzyme

On titration of the apoprotein of ferredoxin-NADP ${ }^{+}$ reductase with 8-mercapto-FAD there is only a minor shift in the absorption spectrum from $520 \mathrm{~nm}$ to $548 \mathrm{~nm}$ for the protein-bound species, with a shoulder at $470 \mathrm{~nm}$ (Fig. 1). The enzyme seems to bind the substituted flavin quite tightly; in fact, the reconstituted protein was chromatographed on Sephadex G-25 to remove the excess flavin before measuring the absorbance. The spectrum remained stable at least for $24 \mathrm{~h}$ at $4^{\circ} \mathrm{C}$ and a week at $-20^{\circ} \mathrm{C}$. The reconstituted 8-mercaptoFAD - enzyme can be easily reduced by NADPH plus regenerating system (see Materials and Methods) (Fig. 1) with the formation of a long-wavelength band absorbing around $720 \mathrm{~nm}$. This form is presumably the neutral radical species, since a similar spectrum was obtained with 8-mercaptoFMN - flavodoxin [2], and since like the neutral radical of FAD in native ferredoxin - NADP ${ }^{+}$reductase, it is obtained in a good yield by admitting low quantities of oxygen to the reduced enzyme [17].

From these observations we can conclude that ferredoxin $\mathrm{NADP}^{+}$reductase binds the thiolate form of 8-mercaptoFAD; the shoulder at $470 \mathrm{~nm}$ is reproducibly present but is not influenced by $\mathrm{pH}$, thus ruling out the possibility of being due to some undissociated 8-mercaptoflavin [2].

\section{Solvent Accessibility \\ of the Flavin Position 8 in Ferredoxin-NADP $P^{+}$Reductase}

By addition of methylmethanethiolsulfonate to the oxidized 8-mercapto-FAD-enzyme, the spectrum is immediately bleached. After addition of dithiothreitol the original spectrum is restored.

The 8-mercapto-FAD - enzyme reacted with iodoacetamide (Fig. 2) at a rate of $77 \mathrm{M}^{-1} \cdot \mathrm{min}^{-1}$ at $25^{\circ} \mathrm{C}$, which is faster than with free flavin [3]. Thus, clearly the flavin reacted while bound to protein. In the case of ferredoxin-NADP ${ }^{+}$reductase, interference by the modification of sulfhydryl groups of the protein should be negligible. The $-\mathrm{SH}$ groups of this flavoprotein are very unreactive towards many sulfhydryl reagent [18]. Specifically the diaphorase activity is not modified by incubation with $10 \mathrm{mM}$ iodoacetamide at $25^{\circ} \mathrm{C}$ for $60 \mathrm{~min}(\mathrm{G}$. Zanetti, unpublished data).

The $8-\mathrm{SCH}_{2} \mathrm{CONH}_{2}-\mathrm{FAD}$ - enzyme is completely nonfluorescent. Thus, as with the native coenzyme, the fluorescence is fully quenched by the protein. The reconstituted enzyme can be reduced by NADPH plus regenerating system (Fig. 3). Complete reduction can be achieved, leaving a small peak at $420 \mathrm{~nm}$; a long-wavelength band can be seen with a maximum at $620 \mathrm{~nm}$. The latter is typical of the neutral radical species of 8-SR-flavins (V. Massey, unpublished results).

The 8-mercapto-FAD - enzyme also reacted with iodoacetic acid $\left(1.92 \mathrm{M}^{-1} \cdot \min ^{-1}\right.$ at $10^{\circ} \mathrm{C}$ ) (data not shown). The spectrum of the product is similar to that of the 8$\mathrm{SCH}_{2} \mathrm{CONH}_{2}-\mathrm{FAD} \cdot \mathrm{enzyme}$ with the peak at $491 \mathrm{~nm}$ instead of $487 \mathrm{~nm}$.

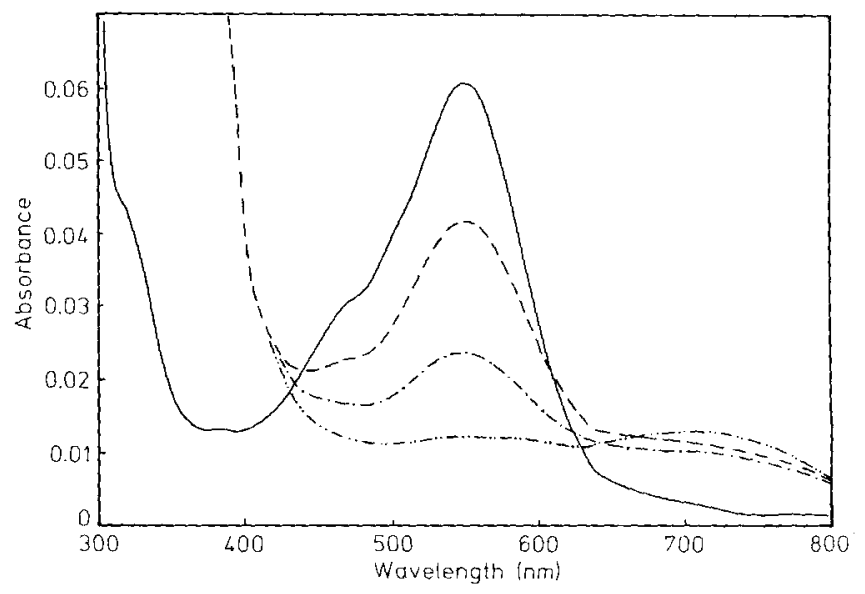

Fig. 1. Effects of $N A D P H$ reduction on ferredoxin- $N A D P^{+}$reductase whose native flavin has been replaced by 8-mercapto-FAD. The reconstituted holoenzyme was filtered through Sephadex G-25 equilibrated in $0.05 \mathrm{M}$ Tris/ $\mathrm{HCl} \mathrm{pH} 7.4\left(25^{\circ} \mathrm{C}\right)$, before taking the spectrum. ( - ) Oxidized enzyme after the anaerobiosis was established; $(\ldots,-) 8 \mathrm{~min}$ after addition of a NADPH-regenerating system; (-..-) $25 \mathrm{~min} ;(\ldots \ldots-) 75 \mathrm{~min}$

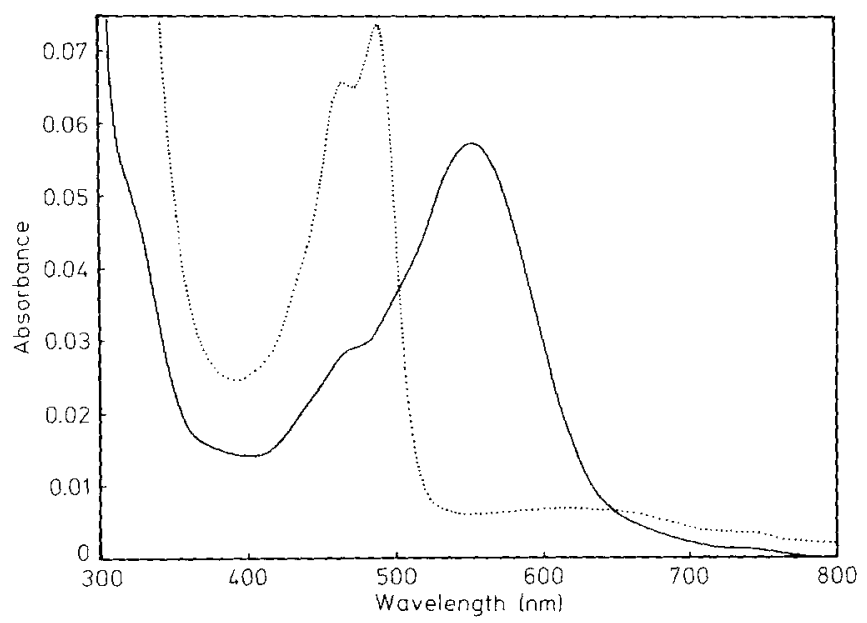

Fig. 2. Conversion of 8 -mercapto-FAD ferredoxin- $N A D P^{+}$reductase to 8-SCH $\mathrm{CHNH}_{2}-\mathrm{FAD} \cdot$ ferredoxin-NADP ${ }^{+}$reductase by the action of iodoacetamide. (-) Oxidized 8-mercapto-FAD-enzyme in $0.05 \mathrm{M}$ Tris/ $\mathrm{HCl}, \quad \mathrm{pH} 7.4, \quad\left(25^{\circ} \mathrm{C}\right) ;(\cdots \cdots \cdots)$ about $30 \mathrm{~min}$ after $10 \mathrm{mM}$ $\mathrm{ICH}_{2} \mathrm{CONH}_{2}$ was added

The effect of $\mathrm{Na}_{2} \mathrm{~S}$ on the 8-Cl-FAD-enzyme was also studied. No reaction was found over a $30-\mathrm{min}$ period. This contrasts strongly with the very rapid reaction of the 8mercapto-FAD-enzyme with $\mathrm{Me}_{2} \mathrm{SO}_{2} \mathrm{~S}$ and iodoacetamide. However, there are several examples of this type of behaviour [3], which implies either a barrier to forming the tetrahedral intermediate involved in these nucleophilic displacements reactions, or to charge repulsion by the protein of the nucleophilic anion. The latter hypothesis should be discarded on the basis of the reaction of the 8-mercapto-FAD - enzyme with the iodoacetate anion.

\section{Catalytic Properties}

of Ferredoxin-NADP $P^{+}$Reductase Reconstituted with FAD Analogues Modified at Position 8

The introduction of a chlorine atom in the 8-position of FAD seems to boost the diaphorase activity of ferredoxin- 


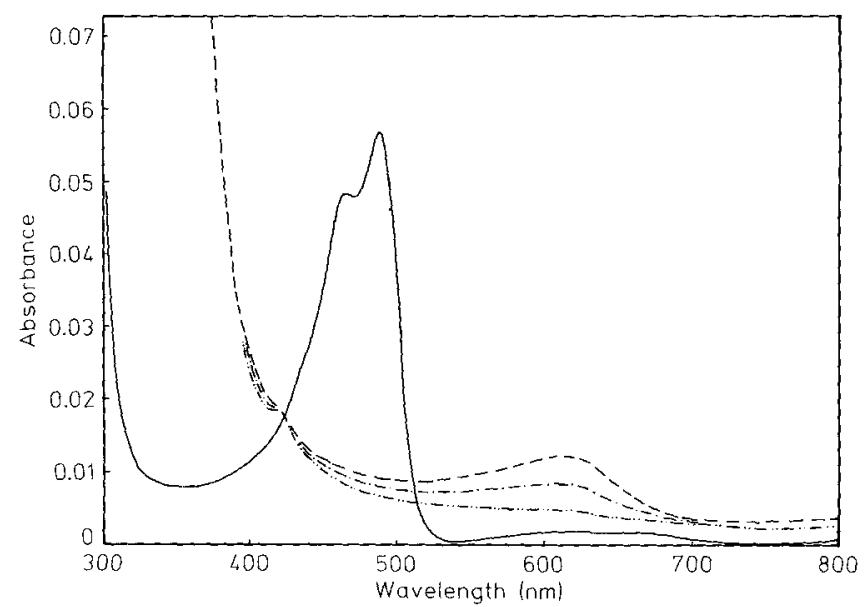

Fig. 3. $\mathrm{NADPH}$ reduction of $8-\mathrm{SCH}_{2} \mathrm{CONH}_{2}-\mathrm{FAD} \cdot$ ferredoxin $-\mathrm{NADP}{ }^{+}$ reductase. The $8-\mathrm{SCH}_{2} \mathrm{CONH}_{2}-\mathrm{FAD}$ - enzyme, obtained by iodoacetamide treatment of 8-mercapto-FAD-enzyme, was dialysed against $0.05 \mathrm{M}$ Tris $/ \mathrm{HCl}, \mathrm{pH} 7.4\left(25^{\circ} \mathrm{C}\right)$ at $4^{\circ} \mathrm{C}$. (-) Oxidized enzyme; (- $-2 \mathrm{~min}$ after addition of a NADPH-regenerating system; (-..-) $10 \mathrm{~min}$; $(-\cdots,-\cdots) 30 \mathrm{~min}$

$\mathrm{NADP}^{+}$reductase not only with ferricyanide (see Table 1) but also with iodonitrotetrazolium. Instead the substitution with a mercapto group in the same position yields an enzyme with very low activity in all the assays tested. Interestingly, alkylation of the thiolate form by iodoacetic acid produced an enzyme with higher diaphorase activity and, what is more important, which has regained activity with ferredoxin.

\section{Binding of 2-Thio-FAD}

by Apoferredoxin- $N A D P^{+}$Reductase:

Solvent Accessibility of Position 2, Reduction by the Substrate and Catalytic Properties of the Reconstituted Enzyme

The apoprotein of ferredoxin-- NADP ${ }^{+}$reductase binds 2thio-FAD quite readily. After gel filtration to remove the excess flavin, the reconstituted holoenzyme shows a spectrum only slightly changed with respect to free 2-thio-FAD [4]. The binding to the protein produces a red shift of peaks from $317 \mathrm{~nm}$ to $325 \mathrm{~nm}$ and from $390 \mathrm{~nm}$ to $405 \mathrm{~nm}$; the major peak at $488 \mathrm{~nm}$ is also red-shifted to $495 \mathrm{~nm}$ and a shoulder at $520 \mathrm{~nm}$ develops.

The exposure to solvent of the 2-position of FAD can be checked by reacting the reconstituted 2-thio-FAD - enzyme with excess methylmethanethiolsulfonate. The free 2-thioflavin anion reacts readily with this thiol reagent to yield the corresponding 2-SSCH${ }_{3}$-flavin disulfide; this reaction is accompanied by a substantial change in the visible absorbance spectrum [4]. Thus, the effect of $\mathrm{Me}_{2} \mathrm{SO}_{2} \mathrm{~S}$ on the 2-thioFAD - enzyme, under non-denaturing conditions, was followed by monitoring the spectral changes induced at $520 \mathrm{~nm}$. There was only a very slow decrease of absorbance of the $500-\mathrm{nm}$ absorption band which became evident only after several days.

The reduction by NADPH plus regenerating system is very rapid to give an almost complete bleaching of the $500-\mathrm{nm}$ band. During the reduction, and on admitting air, transient longwavelength absorption can be observed. This seems to be due to weak charge transfer absorbance between oxidized enzyme and $\mathrm{NADPH}$, and between reduced enzyme and $\mathrm{NADP}^{+}$respectively, rather than to a radical species; in fact, the latter should have a pronounced absorbance maximum at $680 \mathrm{~nm}$, as judged from experiments with 2-thio-FMN-flavodoxin (V. Massey, unpublished).

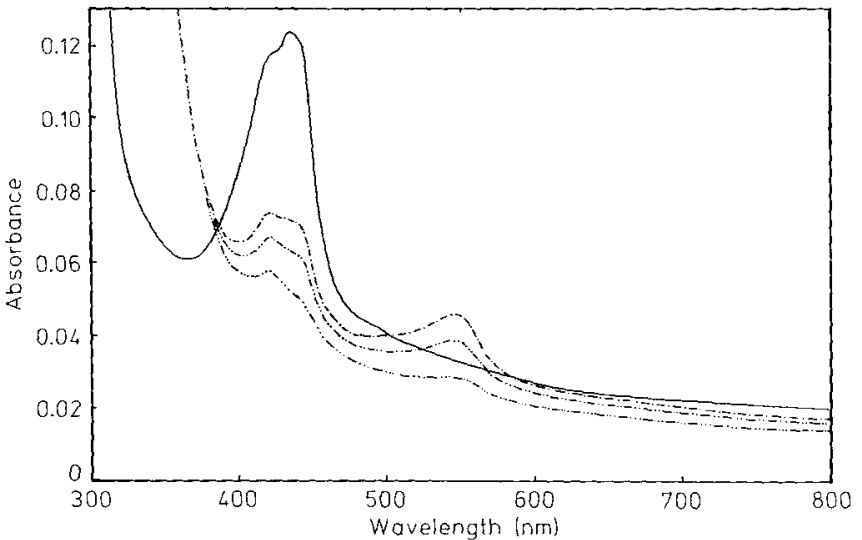

Fig. 4. NADPH reduction of 6-OH-FAD - ferredoxin $-N A D P^{+}$reductase. (- - ) 6-OH-FAD - enzyme after the anaerobiosis was established; $(\cdots,-) 2$ min after a NADPH-regenerating system was added; $(\cdots \cdots \cdots)$ $10 \mathrm{~min} ;(-\cdots-\cdots-) 47 \mathrm{~min}$

The reconstituted 2-thio-FAD - enzyme is catalytically very efficient at least with potassium ferricyanide (Table 1); a ninefold increase is observed, whereas the activity with iodonitrotetrazolium is slightly higher than that of native enzyme. The reaction with ferredoxin is difficult to interpret (see later).

Binding of 6-Hydroxy-FAD to Apoferredoxin-NADP $P^{+}$Reductase: Reduction by the Substrate and Catalytic Properties of the Reconstituted Enzyme

In order to determine the effects of the hydroxy group at position 6 on the properties of the holoenzyme, we studied the binding of 6-OH-FAD to the apoprotein of ferredoxin$\mathrm{NADP}^{+}$reductase. When 6-OH-FAD is added to the apoprotein at $\mathrm{pH} 7.5$, the $423-\mathrm{nm}$ absorption maximum is slightly red-shifted to $435 \mathrm{~nm}$, whereas the $320-\mathrm{nm}$ and $600-\mathrm{nm}$ bands disappeared. The spectrum of the 6-OH-FAD-reconstituted enzyme (Fig. 4) is very similar to the spectrum of free $6-\mathrm{OH}$ FAD at pH5.4 [8], suggesting that ferredoxin-NADP ${ }^{+}$ reductase binds the neutral form of this substituted flavin. Unlike the spectrum of the latter, the spectrum of the 6-OHFAD - enzyme does not change by varying the $\mathrm{pH}$ up to 9.1 . Only above this value were the changes consistent with ionization. Accordingly, the $\mathrm{p} K$ for the dissociation of the $6-$ $\mathrm{OH}-\mathrm{FAD}$ to the anion form has been shifted from $7.1[8]$ to a much higher value. The $\mathrm{p} K$ of the enzyme-bound form has not been determined accurately, due to possible protein denaturation at the high $\mathrm{pH}$ values required. However, the spectrum at $\mathrm{pH} 10.5$ which corresponds roughly to that which would be expected for half ionization, is readily reversed on lowering the $\mathrm{pH}$, even after standing at $0^{\circ} \mathrm{C}$ for $12 \mathrm{~h}$.

The 6-OH-FAD-reconstituted enzyme is easily reduced by NADPH plus regenerating system (Fig. 4). The presence of oxygen caused a rapid generation of a $550-\mathrm{nm}$ peak. By analogy with 6-OH-FMN - electron-transferring flavoprotein [8], this intermediate should be the neutral semiquinone of 6-OH-FAD.

As far as activity is concerned, it should be noted that this holoenzyme has a better capacity to reduce ferredoxin than artificial dyes (Table 1). 
Table 1. Catalytic activities of apoferredoxin $-N A D P^{+}$reductase reconstituted with $F A D$ analogues

\begin{tabular}{|c|c|c|c|c|c|}
\hline \multirow[t]{2}{*}{ FAD analogue } & \multirow{2}{*}{$\begin{array}{l}\text { Midpoint } \\
\text { poten- } \\
\text { tial }^{\text {a }}\end{array}$} & \multicolumn{4}{|c|}{ Activity with } \\
\hline & & $\begin{array}{l}\mathrm{K}_{3} \mathrm{Fe}- \\
(\mathrm{CN})_{6}\end{array}$ & $\begin{array}{l}\text { iodo- } \\
\text { nitro- } \\
\text { tetra- } \\
\text { zolium }\end{array}$ & cyt $c$ & $\begin{array}{l}\text { ferre- } \\
\text { doxin } \\
\rightarrow \text { cyt } c\end{array}$ \\
\hline & $\mathrm{mV}$ & $\%$ & & & \\
\hline FAD & -208 & 100 & 100 & 0 & 100 \\
\hline 1-Deaza-FAD & -280 & 7 & 2 & 0 & 2 \\
\hline 2-Thio-FAD & -126 & 900 & 130 & 18 & 20 \\
\hline 6-OH-FAD & $-265^{\mathrm{b}}$ & 4 & 10 & 1 & 14 \\
\hline 8-Cl-FAD & -152 & 650 & 515 & 13 & 15 \\
\hline .8 -Mercapto-FAD & -290 & 2.5 & 6 & 0.5 & 1 \\
\hline 8-SCH${ }_{2} \mathrm{COOH}-\mathrm{FAD}$ & -208 & 9 & 30 & 2 & 13 \\
\hline $8-\mathrm{SCH}_{2} \mathrm{CONH}_{2}-\mathrm{FAD}$ & - & 24 & 61 & 6.5 & 8 \\
\hline
\end{tabular}

a Midpoint potential of riboflavin level

${ }^{b} \mathrm{P}$. Hemmerich, unpublished data

Comparison of the Catalytic Competency of Ferredoxin-NADP ${ }^{+}$Reductase Reconstituted with Various FAD Analogues

The apoprotein of ferredoxin-NADP ${ }^{+}$reductase was reconstituted with different analogues of FAD and the activities with different electron acceptors tested. In Table 1 the oxidation-reduction potentials of the free FAD analogues are reported, together with the activities of the reconstituted holoenzyme.

Examining first the ferricyanide reductase activity, it can be seen that 2-thio-FAD, with a redox potential $82 \mathrm{mV}$ more positive than FAD, produces a holoenzyme with $900 \%$ higher catalytic rate than FAD-reconstituted enzyme. At the other end of the oxidation-reduction scale, 8-mercapto-FAD has a redox potential $82 \mathrm{mV}$ more negative than FAD and gives an enzyme with $1 / 40$ of the rate of the FAD - enzyme. Thus, the catalytic rate of ferredoxin $-\mathrm{NADP}^{+}$reductase may be controlled by the input or output of electrons to the bound flavin. In fact, when ferricyanide is the electron acceptor, the modification of the flavoprotein redox potential obtained through the substitution of FAD with flavin analogues of different redox potential results in a variation of the rate over a 100 -fold range. The semilog plot of rate versus flavin two-electron potential [19] shows that a linear relationship exists (with the exception of $8-\mathrm{SCH}_{2} \mathrm{COOH}-\mathrm{FAD}$ - enzyme) and the sign of the slope implies that it is reduction of the enzyme-bound FAD (or analogue) which is rate-determining. No such simple relation with the flavin redox potential is found for iodonitrotetrazolium reductase activity.

On the other hand, the examination of the data (Table 1) obtained using the physiological one-electron carrier ferredoxin reveals a different pattern. The rate with this acceptor is about tenfold lower than with ferricyanide. There is no linear free energy relationship between redox potential and rate in the range tested. With the exception of 1-deaza-FAD, all the other FAD analogues when reconstituted with the apoprotein conferred to the enzyme the ability to reduce cytochrome $c$ directly to various extents. This activity, which seems absent in the native ferredoxin - NADP ${ }^{+}$reductase, is partially inhibited by addition of superoxide dismutase, thus suggesting a mediation of superoxide radical in the cytochrome reduction. On the other hand, the inhibition by superoxide dismutase is less pronounced or even absent when reduction of cytochrome $c$ is measured in the presence of ferredoxin; thus it is not clear if a direct reduction of cytochrome $c$ is still taking place. In the case of the 6-OH-FAD-enzyme and of the $8-\mathrm{SCH}_{2} \mathrm{COOH}$ FAD - enzyme, the difference between the two reductase activity levels (see last two columns of Table 1) leaves no doubts on the presence of a specific ferredoxin reductase activity; vice versa, the data obtained with the 2-thio-FAD, 8-Cl-FAD and $8-\mathrm{SCH}_{2} \mathrm{CONH}_{2}-\mathrm{FAD}$ do not give a clear answer, a different assay being required to measure the ferredoxin reductase activity of these reconstituted enzymes.

\section{Isoelectrofocusing Experiments}

In order to detect whether subtle modifications were induced in the apoprotein by binding to differently substituted flavins, we analyzed the isoelectrofocusing patterns of the different reconstituted holoenzymes. The apoprotein, on binding the various FAD analogues, reformed exactly the same species as with normal FAD.

\section{DISCUSSION}

One of the more challenging problem encountered in flavoprotein biochemistry is to understand the ways in which the versatile chemistry of the isoalloxazine nucleus becomes restricted to a well defined reaction pathway by the interaction with the apoprotein moiety of a particular flavoenzyme. A further problem to be solved is to determine which way electrons from substrates enter or leave the isoalloxazine nucleus of the flavin coenzyme.

According to Massey and Hemmerich [1], ferredoxin$\mathrm{NADP}^{+}$reductase has been assigned to class IV of flavoproteins (the dehydrogenases/electron transferases) on the basis of its reaction mechanism: it accepts electrons from a oneelectron carrier (i.e. ferredoxin) and donates them to a twoelectron carrier (i.e. $\mathrm{NADP}^{+}$). The analysis of the results reported in the present paper clearly indicates that the properties of ferredoxin $-\mathrm{NADP}^{+}$reductase agree quite well with those of other class IV flavoproteins. The fact that the apoferredoxin - NADP ${ }^{+}$reductase binds both the thiolate form of 8-mercapto-FAD and the neutral form of the 6-OHFAD is indicative of the lack of a positively charged group near the $-N_{1}-C_{2}=O$ position of the pyrimidine subnucleus of the flavin. This is keeping with the well known stabilization of the blue neutral semiquinone by ferredoxin $-\mathrm{NADP}^{+}$reductase and generally by flavodehydrogenases of class IV as well [1].

The ferredoxin $-\mathrm{NADP}^{+}$reductases reconstituted with various flavin analogues (8-mercapto-FAD, 2-thio-FAD, 8$\mathrm{SCH}_{2} \mathrm{CONH}_{2}-\mathrm{FAD}$, 6-OH-FAD) are reducible by NADPH. A relationship with the midpoint potential of the flavin analogues is apparent. Thus, the 2-thio-FAD - enzyme is reduced more rapidly than the 8 -mercapto-FAD - enzyme or the 6-OH-FAD - enzyme. In addition, a linear relationship is obtained by analysis of the catalytic activity of the substituted enzymes with ferricyanide as electron acceptor. In the case of the native enzyme, the rate-limiting step in the ferricyanide reductase reaction has been shown to be the reduction of the flavin by NADPH [20]. Thus, the observed dependence of the ferricyanide reductase activity on the redox potential of the flavin probably reflects simply the greater ease of reduction the higher the redox potential of the flavin. With ferredoxin as acceptor, electron transfer between flavin and iron-sulfur 
center is known to take place in a complex of the two proteins [21]. Hence, the catalytic velocity in this reaction is subject to geometrical constraints which would not apply in the case of simple molecules such as ferricyanide, e.g. to subtle differences in binding orientation or to differences in the binding constant for the flavoprotein-ferredoxin complex.

A study of the degree of accessibility to the solvent of the isoalloxazine nucleus in ferredoxin $-\mathrm{NADP}^{+}$reductase has provided interesting results. As already pointed out $[3,4]$, the reactivity of 8-substituted flavins and of 2-thioflavins towards specific reagents can be used to obtain information on the accessibility of the solvent to these particular positions of the protein-bound flavin. In ferredoxin $-\mathrm{NADP}^{+}$reductase we seem to have a clear-cut situation: while the 8-position of the isoalloxazine nucleus is fully reactive to methylmethanethiolsulfonate and iodoacetamide, the 2-position is completely unreactive. These results suggest that the 8-position of the flavin in ferredoxin $-\mathrm{NADP}^{+}$reductase is freely available to solvent, whereas the flavin pyrimidine subnucleus must be completely buried by amino acid residues within the protein. In regard to the enhancement of the rate of reaction of the 8mercapto group with iodoacetamide in the 8-mercaptoFAD - enzyme compared with free 8-mercaptoflavin, it has been proposed that the enhancement could be due to a decreased polarity of the protein environment in proximity of position 8 of the flavin [3].

A final comment should be made on the isoelectrofocusing data. This technique is not able to discriminate between native enzyme and the holoenzyme reconstituted with different flavin analogues, all these forms presenting nearly identical isoelectrophoretic patterns. Such a result indicates that substitution at the isoalloxazine nucleus induces only minor, local changes without producing gross conformational modifications of the protein.

This work was supported by grants from Consiglio Nazionale delle Ricerche of Italy and the United States/Italy cooperative science program C.N.R./N.I.G.M.S. and by grant GM-11106 from the National Institutes of Health.

\section{REFERENCES}

1. Massey, V. \& Hemmerich, P. (1980) Biochem. Soc. Trans. 8, 246-257.

2. Massey, V., Ghisla, S. \& Moore, E. G. (1979) J. Biol. Chem. 254, 9640-9650.

3. Schopfer, L. M., Massey, V. \& Claiborne, A. (1981) J. Biol. Chem. 256, $7329-7337$.

4. Claiborne, A., Massey, V., Fitzpatrick, P. F. \& Schopfer, L. M. (1982) J. Biol. Chem. 257, 174-182.

5. Burnett, R. M., Darling, G. D., Kendall, D. S., LeQuesne, M. E., Mayhew, S. G., Smith, W. W. \& Ludwig, M. L. (1974) J. Biol. Chem. $249,4383-4392$.

6. Hofsteenge, J., Vereijkem, J. M., Beintema, J. J., Wierenga, R. K. \& Drendth, J. (1980) Eur. J. Biochem. 113, 141-150.

7. Thieme, R., Pai, E. F., Schirmer, R. H. \& Schulz, G. E. (1981) J. Mol. Biol. 152, 763-782.

8. Mayhew, S. G., Whitfield, C. D., Ghisla, S. \& Schuman-Jörns, M. (1974) Eur. J. Biochem. 44, 579-591.

9. Zanetti, G. \& Curti, B. (1980) Methods Enzymol. 69, 250-255.

10. Karplus, P. A. \& Herriot, J. R. (1982) in Flavins and Flavoproteins (Massay, V. \& Williams, C. H., Jr, eds) pp. 28-31, Elsevier/NorthHolland, New York.

11. Zanetti, G., Cidaria, D. \& Curti, B. (1982) Eur. J. Biochem. 126, $453-$ 458.

12. Spencer, R., Fisher, J. \& Walsh, C. (1976) Biochemistry, I5, 10431053.

13. Moore, E. G., Ghisla, S. \& Massey, V. (1979) J. Biol. Chem. 254, $8173-8178$

14. Zanetti, G. (1981) Plant Sci. Lett. 23, 55-61.

15. Righetti, P. G. \& Drysdale, J. W. (1976) Isoelectric Focusing, pp. $450-$ 463, North-Holland, Amsterdam.

16. Gozzer, C., Zanetti, G., Galliano, M., Sacchi, G. A., Minchiotti, L. \& Curti, B. (1977) Biochim. Biophys. Acta, 485, 278-290.

17. Zanetti, G. \& Curti, B. (1982) in Flavins and Flavoproteins (Massey, V. \& Williams, C. H., Jr, eds) pp. 667-671, Elsevier/North-Holland, New York.

18. Zanetti, G. \& Forti, G. (1969) J. Biol. Chem. 244, 4757-4760.

19. Light, D. R. \& Walsh, C. (1980) J. Biol. Chem. 255, 4264-4277.

20. Massey, V., Matthews, R. G., Foust, G. P., Howell, L. G., Williams, C. H., Jr, Zanetti, G. \& Ronchi, S. (1970) in Pyridine NucleotideDependent Dehydrogenases (Sund, H., ed.) pp. 393-409, SpringerVerlag, New York.

21. Foust, G. P., Mayhew, S. G. \& Massey, V. (1969) J. Biol. Chem. 244, $964-970$.

G. Zanetti and B. Curti, Dipartimento di Fisiologia e Biochimica Generali,

Sezione Chimica Biologica, Università di Milano, via Celoria 26, I-20133 Milano, Italy

V. Massey, Department of Biological Chemistry, The University of Michigan,

Ann Arbor, Michigan, USA 48109 